\title{
Correction to: Age-related expression of Neurexin1 and Neuroligin 3 is correlated with presynaptic density in the cerebral cortex and hippocampus of male mice
}

\author{
Dhiraj Kumar • M. K. Thakur
}

Published online: 4 September 2019

(C) American Aging Association 2019

\section{Correction to: GeroScience (2015) 37:17 \\ https://doi.org/10.1007/s11357-015-9752-6}

The corresponding author noticed in his published paper that the images (30 weeks, CC, 10, 30 and 50 weeks DG) of Fig. $3 b$ are inadvertently duplicated with the images of Fig. 3a. Now, these images have been replaced in the corrected panel (Fig. 3b) below. 


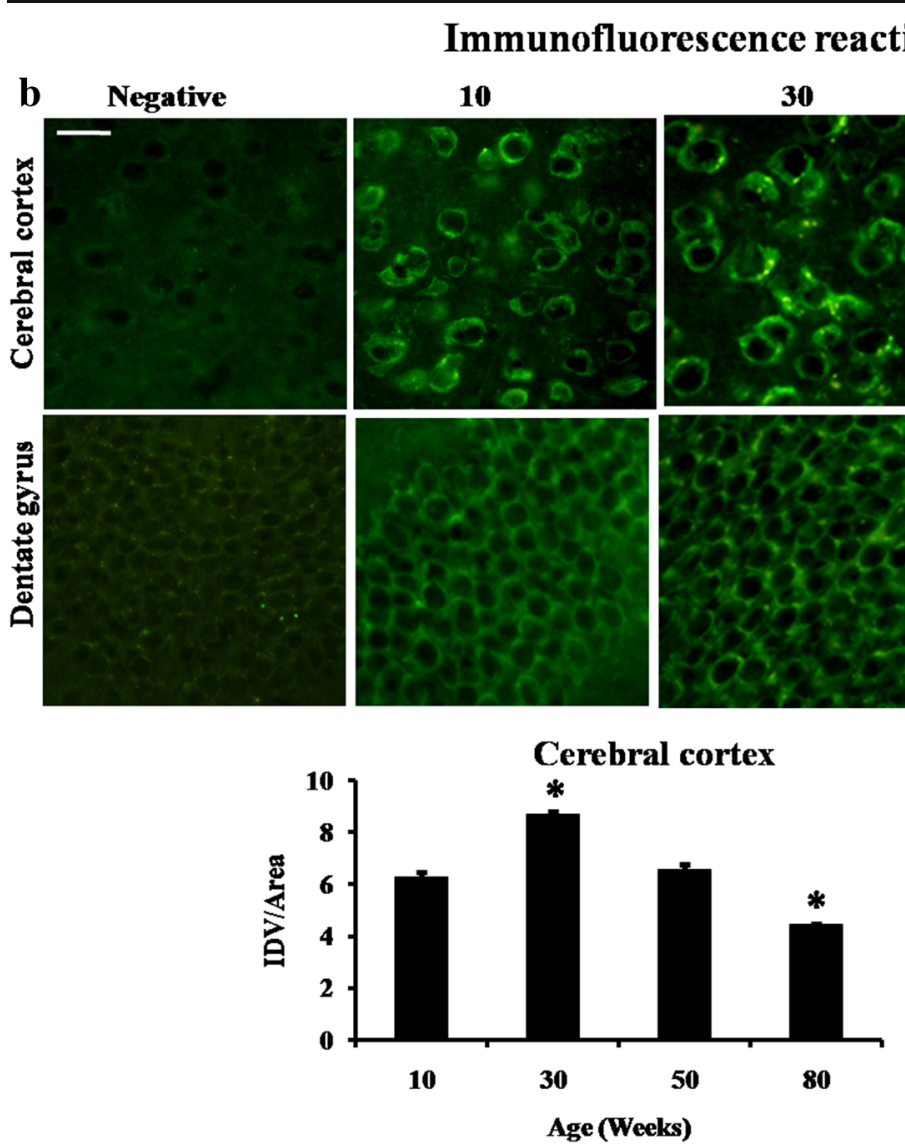

50
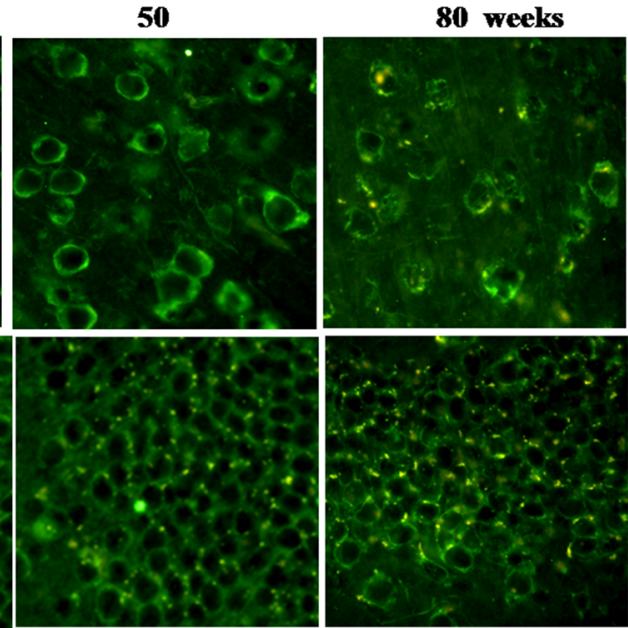

Dentate gyrus

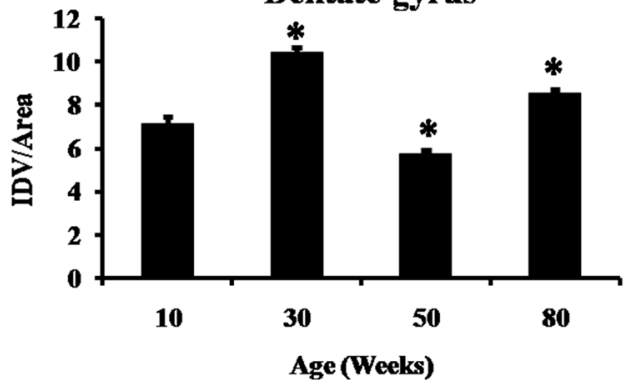

Publisher's note Springer Nature remains neutral with regard to jurisdictional claims in published maps and institutional affiliations. 